\title{
Non-native rainbow trout (Oncorhynchus mykiss) occupy a different trophic niche to native Breede River redfin (Pseudobarbus burchelli) which they replace in South African headwater streams
}

\author{
Jeremy M. Shelton ${ }^{1,2,3}$ | Matthew S. Bird ${ }^{4}$ | Michael J. Samways ${ }^{2}$ | Jenny A. Day ${ }^{3,5}$
}

\author{
${ }^{1}$ Centre for Invasion Biology, Stellenbosch \\ University, Stellenbosch, South Africa \\ ${ }^{2}$ Department of Conservation Ecology \\ and Entomology, Stellenbosch University, \\ Stellenbosch, South Africa \\ ${ }^{3}$ Freshwater Research Centre, Scarborough, \\ South Africa \\ ${ }^{4}$ DST/NRF Research Chair in Shallow Water \\ Ecosystems, Nelson Mandela Metropolitan \\ University, Port Elizabeth, South Africa \\ ${ }^{5}$ University of Cape Town, Rondebosch, \\ Cape Town, South Africa

\section{Correspondence} \\ J. M. Shelton, Centre for Invasion Biology, \\ Stellenbosch University, Stellenbosch, South \\ Africa. \\ Email: jembejem@gmail.com
}

\begin{abstract}
Recent research has revealed that non-native rainbow trout Oncorhynchus mykiss have largely replaced a native cyprinid, the Breede River redfin Pseudobarbus burchelli, as the dominant species of fish in many headwater streams in the Cape Floristic Region (CFR) of South Africa. Moreover, differences in the composition of benthic communities in CFR headwater streams with and without trout suggest that trout do not functionally compensate for the native redfin which they have replaced in these food webs. In this study, we used gut content and stable isotope analyses to characterise and compare the trophic niches and diet compositions of allopatric populations of trout and redfin in six CFR headwater streams (three containing trout, three containing redfin). Results indicate that native redfin exploit a broader trophic niche, and a more omnivorous diet, than do trout. Gut content analyses showed terrestrial invertebrates to be an important prey source for trout, which could potentially offset predation pressure on aquatic invertebrates and explain why benthic invertebrate density in streams with trout is higher than that in streams with no trout. Contrastingly, redfin diet appeared to be dominated by aquatic invertebrates, with terrestrial prey a less important food item in the guts of redfin. That redfin and trout exploit nonequivalent trophic niches may have consequences for benthic community composition in CFR headwater streams, and this study highlights the importance of quantifying how the functional role of predators changes following a predator replacement for understanding and managing the consequences of non-native predator invasions.
\end{abstract}

KEYWORDS

gut contents, predator replacement, stable isotopes, terrestrial subsidy, trophic omnivory

\section{1 | INTRODUCTION}

The introduction of species outside of their natural range is a principal driver of the human-induced biodiversity crisis (Mack et al., 2000), causing species extinctions, habitat degradation and changes in the structure and functioning of ecosystems the world over (Leprieur et al., 2006). Introduced predators, in particular, have had devastating and far-reaching effects in recipient systems (Cox \& Lima, 2006). This is because predators can influence community structure at multiple trophic levels through a combination of direct and indirect top-down effects (Pace, Cole, Carpenter, \& Kitchell, 1999). The consequences of a predator introduction for the receiving community will depend upon 
how the introduced predator changes the structure and function of the native predator assemblage. In situations where native predators are replaced by introduced predators, the degree to which the rest of the community is affected may then depend on how closely the functional role performed by the introduced predator matches that of the native predator(s) (Chalcraft \& Resetarits, 2003). Understanding how the functional role of predators in a system changes following a predator introduction is thus critical for managing non-native predator invasions (Benjamin, Fausch, \& Baxter, 2011).

Salmonids are among the most widely introduced predatory freshwater fish (Crawford \& Muir, 2008) and have often modified native predator assemblages where they have become invasive (Cambray, 2003; McDowall, 2006; Rahel, 2000; Simon \& Townsend 2003; Townsend, 2003). In many instances, introduced salmonids perform a functional role that is different from that performed by native predators, and community-wide effects have ensued. For example, in New Zealand, brown trout Salmo trutta have replaced native galaxiids Galaxias spp. in many streams (Townsend \& Crowl, 1991), and because they have a foraging behaviour that differs from that of the galaxiids (McIntosh \& Townsend, 1995), their impact has extended beyond the replacement of native fish, causing shifts in prey assemblage structure and ultimately modifying the entire stream food web (Flecker \& Townsend, 1994; Mclntosh \& Townsend, 1996; Townsend, 2003). In South Africa (but outside of the Cape Floristic region (CFR)), rainbow (Oncorhynchus mykiss) and brown trout have been shown to differ from the native fish they replace in their consumption of emerging aquatic insects, thus affecting both aquatic and adjacent terrestrial food webs through this replacement (Jackson et al., 2016).

Rainbow trout, a salmonid native to Eastern Russia and Pacific North America, was brought to the CFR, a global biodiversity hotspot in the south-western corner of South Africa in 1897 for angling purposes and is now present in all of the regions' major catchments (Scott et al., 2006). In the CFR, rainbow trout (hereafter "trout") may represent the greatest threat of all 20 established non-native fish species because they are well adapted to mountain stream habitats which function as refuges for aquatic biodiversity within the regions' highly degraded riverscapes (Shelton, Samways, \& Day, 2014a,b). Knowledge about how trout alter predation dynamics in these systems is essential if management of this non-native species is to be effective in the CFR.

Results from recent comparative field studies conducted in the CFR have shown that in systems where trout establish at relatively high densities, they displace a formerly abundant native cyprinid, the Breede River redfin Pseudobarbus burchelli (Smith 1841) through predation (Shelton et al., 2014a), and this displacement appears to have released herbivorous aquatic invertebrates from predation, apparently leading to cascading effects on benthic algae in invaded systems (Shelton et al., 2014b). These findings imply that trout do not functionally compensate for native redfin, which they have replaced, and may thereby have altered top-down control of aquatic invertebrates in these systems. This could be because trout change the overall fish density or biomass in invaded streams or because the trophic niche that trout occupy is different to that occupied by $P$. burchelli (hereafter "redfin"). That the mean total biomass of fish in streams with and without trout was similar (Shelton et al., 2014b) implies the latter and suggests that trout are weaker regulators of herbivorous invertebrates than are redfin.

The feeding habits of redfin have not been well studied, but available information suggests that they forage among the benthos (Chakona \& Swartz, 2013) and consume an omnivorous diet (Cambray \& Stewart, 1985; de Wet, 1990). Studies examining redfin gut contents suggest that aquatic invertebrates dominate their diet, but that plant material such as algae and detritus is also commonly consumed (Cambray \& Stewart, 1985; Esterhuizen, 1978; de Wet, 1990). Rainbow trout are carnivorous (Cambray, 2003), and while also capable of benthic foraging, generally feed on aquatic invertebrates drifting in the water column and on the water surface, and can acquire a substantial proportion of their diet from terrestrial invertebrates that fall into the stream from the riparian zone (Baxter, Fausch, Murakami, \& Chapman, 2004; Nakano, Miyasaka, \& Kuhara, 1999). If terrestrial invertebrates feature strongly in the diet of trout in CFR streams, then this may offset their impact on benthic invertebrates and potentially explain why they suppress herbivorous invertebrates less strongly than do redfin. In this study, we predicted that trophic niche and diet composition of trout would differ from that of redfin. Specifically, we hypothesised (i) that redfin consume a more omnivorous diet than do trout, (ii) that redfin exploit a broader trophic niche than do trout and (iii) that redfin rely more strongly on benthic invertebrates and plant material than do trout, while trout rely more strongly on terrestrial invertebrates than do redfin. These hypotheses were examined using a combination of complementary approaches including gut contents analysis (GCA) and stable isotope analysis (SIA).

\section{2 | MATERIALS AND METHODS}

\section{1 | Study area}

This study was conducted in six headwater streams in the upper Breede River catchment in the CFR (Fig. S1), including three troutfree streams where redfin abundance is relatively high (namely the Tierkloof, Tierstel and Waaihoek streams), and three streams (namely the Groothoek, Klip and Kraal streams) where trout have replaced redfin and are now the only species of fish present (Shelton et al., 2014a). We did not sample fish at sites where trout and redfin co-occurred because we were primarily interested in the trophic niches of allopatric populations as this is representative of the most common situation in CFR streams (Shelton et al., 2014a). Moreover, sympatric populations of trout and redfin were relatively uncommon in our study area, and where they do co-occur their trophic niches may change as a result of interspecific interactions. As is commonly the case in the upper Breede River catchment, redfin at our study sites co-occurred with two other small-bodied native species namely the Cape Kurper Sandelia capensis and the Cape galaxias Galaxias zebratus (see Shelton et al., 2014a for estimates of species densities). 
Trout densities at our sampling sites ranged from $21.51 \pm 1.62$ to $102.32 \pm 7.36$ fish $100 \mathrm{~m}^{-2}$ and redfin densities from $9.65 \pm 0.79$ to $103.00 \pm 6.87100 \mathrm{~m}^{-2}$ (Shelton et al., 2014a). All samples were collected from a randomly selected $200 \mathrm{~m}$ reach in each stream where access to the site was practical. Our study reaches were narrow $(<4 \mathrm{~m}$ wide), shallow ( $<0.30 \mathrm{~m}$ deep) and clear, dominated by cobble and boulder substrates and free from the influence of human activities and non-native species (other than rainbow trout). The area experiences a mediterranean climate with warm, dry summers and cool, wet winters, receiving a mean annual rainfall of $\sim 800 \mathrm{~mm}$ (Steynor, Hewitson, \& Tadross, 2009). Natural vegetation covering the mountains is predominantly indigenous Sandstone Fynbos (a diverse assemblage of low growing, fine leaved, sclerophyllous shrubs), while riparian vegetation comprises broad-leaved woody indigenous species of perennial shrubs and small trees (de Moor \& Day, 2013). The underlying geology is dominated by hard, quartzitic sandstones, and the streams flowing over this substratum are acidic, oligotrophic and low in dissolved solids (de Moor \& Day, 2013).

\section{2 | Data collection}

\subsection{1 | Gut contents}

Gut contents analysis was used to obtain a high-resolution, summer snapshot of trout and redfin diets at the study sites (Gelwick \& Matthews, 2007). Between 20 and 30 trout or redfin were collected from each stream with a 3-m seine net during summer low flow conditions (16 February-19 March 2010). Fish were euthanised and preserved by freezing for examination of gut contents in the laboratory (Gido \& Franssen, 2007). To relate the gut contents of fish to the prey availability in the stream, benthic and drifting invertebrates were sampled at each study site prior to (but on the same day as) fish sampling. Ten benthic invertebrate samples were collected from random locations at each site using a $30 \times 30 \mathrm{~cm}$ box sampler (250 $\mu \mathrm{m}$ mesh). Drifting invertebrates were sampled using three drift nets that had square $30 \times 30 \mathrm{~cm}$ openings, and a net depth of $60 \mathrm{~cm}(250 \mu \mathrm{m}$ mesh diameter), set for $1 \mathrm{hr}$ each. Nets were anchored to the streambed side by side (at right angles to the direction of flow) in riffles, using metal stakes. Nets were positioned such that they extended $5 \mathrm{~cm}$ above the water surface to ensure that invertebrates drifting on the water surface, as well as those drifting in the water column, were captured. All sampling was conducted between 15:00 hr and 17:00 hr, and all invertebrate samples were preserved in $70 \%$ ethanol.

\subsection{2 | Stable isotopes}

In addition to GCA, which provides detailed information about foods recently ingested, stable isotope analysis (SIA) was used to obtain a coarser-resolution, time-integrated picture of fish trophic niches (Gelwick \& Matthews, 2007). Samples for SIA were collected from trout and redfin tissue to ascertain whether they occupy different trophic niches in the study streams. A randomly selected subset of the fish collected for GCA was subjected to SIA: 15 redfin from both Tierstel and Waaihoek streams, 16 redfin from Tierkloof stream and 16 trout from each of the Groothoek, Klip and Kraal streams, giving a total of $n=46$ for redfin and $n=48$ for trout. A 5-mm-diameter plug of dorsal muscle tissue was removed from behind the dorsal fin (Clarke, Vidergar, \& Bennett, 2005) and frozen for measurement of isotopic values. Aquatic invertebrates were also collected for SIA to account for ambient differences in baseline isotopic signatures among the study streams (Anderson \& Cabana, 2007). Aquatic invertebrates were collected by disturbing the substrate (by kicking and brushing with hands) and holding the net $(30 \times 30 \mathrm{~cm}$ square frame, $250 \mu \mathrm{m}$ mesh diameter) downstream to collect the material that became dislodged. Each sample was transferred into a 1-L plastic bottle containing stream water and transported back to a field laboratory and processed within $2 \mathrm{hr}$ of collection.

\section{3 | Laboratory procedures}

\subsection{1 | Gut contents}

In trout, the foregut comprises a true stomach containing gastric caeca (finger-like foldings of stomach walls) and is easily distinguishable from other sections of the digestive tract. Redfin, on the other hand, have a less distinct stomach, and in this study, we analysed only the section from the oesophagus to the end of the first $\mathrm{U}$-shaped bend in the foregut, as this is where the most recently eaten, and most easily identifiable prey items occur (Cambray, 1983; Whitehead, Weyl, \& Bills, 2007). The procedure for fish dissection and gut content examination followed that described by Gelwick and Matthews (2007). All food items present in the guts were removed, placed in a petri dish, sorted and identified under a dissecting microscope. Initially, gut contents were sorted into broad categories including aquatic invertebrates, terrestrial invertebrates, unidentifiable invertebrate remains, algae, detritus and other (which included invertebrate pupae and eggs). Aquatic invertebrates were further identified to lowest feasible taxonomic level and assigned to one of five functional feeding groups (FFGs) including collector-gatherers (CG), grazer-scrapers (GS), filter feeders (FF), shredders (SH) and predators (PR) (Cummins, Merritt, \& Berg, 2008). Terrestrial invertebrates were identified to order, or class when order could not be distinguished, using Picker, Griffiths, and Weaving (2004). All individuals within a taxon in each stomach were combined, blot-dried for $30 \mathrm{~s}$ on filter paper and weighed to the nearest $0.0001 \mathrm{~g}$ as an estimate of the wet weight of that taxon in the fish's stomach (Hyslop, 1980). Similarly, blotted wet weight was also estimated for the nonanimal prey categories.

\subsection{2 | Stable isotopes}

Live invertebrate samples were examined under a dissecting microscope, and all collector-gatherers were removed for use isotopic 
baselines for each site. Ideally, we would have used long-lived primary consumers such as grazing snails and filter-feeding mussels for this purpose (as recommended by Cabana \& Rasmussen, 1996; Post, 2002), but such taxa were not present in the study streams. The collector-gatherer invertebrates were kept alive for $24 \mathrm{hr}$ to ensure clearance of their guts (Cucherousset, Aymes, Santoul, \& Céréghino, 2007) and then euthanised and preserved by freezing. All isotope samples were freeze-dried for $24 \mathrm{hr}$ and then ground to a fine powder using mortar and pestle. Approximately $1 \mathrm{mg}$ of dried sample of fish or invertebrates was packaged in a tin cup and analysed for carbon and nitrogen isotopic ratios at the University of Cape Town Archaeology Department Stable Isotope Laboratory. Samples were combusted, and isotope signatures were measured in a Thermo 1112 Elemental Analyser interfaced via a Thermo Conflo II to a Thermo Delta XP Plus stable light isotope mass spectrometer and reported relative to international standards.

\section{4 | Data analysis}

\subsection{1 | Gut contents}

As several of our food categories were not abundance-based (e.g. algae, detritus and unidentifiable invertebrate remains), the gut content composition of each individual fish was summarised by calculating the percentage by blotted wet weight (\%W) of each food type (Cortés, 1997). Multivariate analyses were used to examine differences in niche breadth and diet composition between trout and redfin. A similarity matrix was calculated from $\ln (x+1)$ transformed \%W dietary data and a principal coordinate analysis (PCO, Anderson, Gorley, \& Clarke, 2008) ordination used to visualise differences in trout and redfin diet compositions. PERMANOVA, a nonparametric, permutation-based analogue of traditional ANOVA/ MANOVA (Anderson et al., 2008) was used to compare diet composition between trout and redfin. Analysis of similarity percentages (SIMPER, Clarke \& Warwick, 2001) was then used to identify the food items contributing most to the dissimilarity in diet composition between trout and redfin. Finally, we used the test for homogeneity of multivariate dispersions (PERMDISP, Anderson et al., 2008), to ascertain whether there was a significant difference in diet breadth between redfin and trout (Correa \& Winemiller, 2014). As we were interested in whether trout and redfin differ in the functional role they perform in stream communities, diets were also compared using a set of coarser categories comprising groups of functionally similar food types. Gut contents were grouped into ten different categories including the five FFGs of aquatic invertebrate, terrestrial invertebrates, unidentifiable invertebrate remains, algae, detritus and other. A multivariate PERMANOVA was used to test for differences in the overall composition of gut contents between species, and univariate PERMANOVAs were then used to assess differences between species in the percentage composition of each food source separately. A two-way nested design was adopted for all PERMANOVA and PERMDISP tests, to examine the effect of the fish species (fixed factor) and site (a random, nested factor) on the different response variables. The Bray-Curtis measure of dissimilarity was used in multivariate models, and Euclidean distance was used for univariate models. All models were run using 9999 permutations of the residuals under a reduced model.

Feeding selectivity was investigated by relating the proportional abundance of each invertebrate group (the five aquatic FFGs and terrestrial invertebrates) to its proportional availability in the stream environment. Prey abundance in fish guts was related to prey availability in the benthos and in the drift using Strauss' (1979) linear electivity index, L:

$$
L_{i}=r_{i}-p_{i}
$$

where $r_{i}$ and $p_{i}$ are the proportional abundances of the different prey types in fish diet and environment respectively. $L$ ranges from -1 to +1 , with negative values indicating avoidance of a prey item, and positive numbers indicating selection for a prey item. We averaged the proportional abundance of FFGs from the ten benthic samples, and aquatic and terrestrial invertebrates from the three drift samples, at each site to relate to the proportional abundance of these food types in fish guts at the sites. Selectivity values based on box sample availability estimates were used to ascertain whether trout and redfin differed in their selection of each of the five FFGs of aquatic invertebrates, while selectivity values based on prey availability in the drift were used to ascertain whether selection of aquatic invertebrates (i.e. all FFGs combined) versus terrestrial invertebrates differed between trout and redfin. Two-way univariate, nested PERMANOVAs were used to test for the effects of species (fixed factor) and site (random, nested factor) on prey selectivity. All distance-based univariate and multivariate analyses of gut contents and feeding selectivity were performed using PRIMER-E (Clarke \& Warwick, 2001) with the add-on package PERMANOVA+ (Anderson et al., 2008). We opted not to use a correction factor (such as Bonferroni) for the multiple tests of gut contents and feeding selectivity due to the corresponding increase in the probability of type II errors, which are believed to be as important, if not more important, than type I errors in the context of ecological studies (Houlahan, Keddy, Makkay, \& Findlay, 2006; Nakagawa, 2004). Furthermore, the Bonferroni procedure has been criticised (Garamszegi, 2006; Moran, 2003; Perneger, 1998) as being inappropriately conservative as it is concerned with the general null hypothesis (that all null hypotheses are true simultaneously), which is seldom appropriate in a biological context; this is no exception in the current study. The approach taken here, as recommended by various other workers in ecology and biology (e.g. Bland \& Altman, 1995; Cabin \& Mitchell, 2000), is to interpret significant results $(p<.05)$ with caution if there are only one or two significant variables out of a group of tested variables.

\subsubsection{Stable isotopes}

We conducted a quantitative assessment of differences in fish trophic niches after intersite differences in $\delta^{15} \mathrm{~N}$ and $\delta^{13} \mathrm{C}$ of basal 
resources among sampling sites had been accounted for (Anderson \& Cabana, 2007; Cabana \& Rasmussen, 1996; Vander Zanden \& Rasmussen, 1999). To achieve this, we first converted $\delta^{15} \mathrm{~N}$ to trophic position (TP) for each individual fish using the equation of Vander Zanden and Rasmussen (1999):

$$
\mathrm{TP}_{\text {fish }}=\lambda+\frac{\left(\delta^{15} \mathrm{~N}_{\text {fish }}-\delta^{15} \mathrm{~N}_{\text {baseline }}\right)}{\Delta^{15} \mathrm{n}}
$$

where $\mathrm{TP}_{\text {fish }}$ is the trophic position of a fish, $\lambda$ is the trophic position of the baseline ( $\lambda$ assumed to be 2 for primary consumers, in this case collector-gatherers), $\delta^{15} \mathrm{~N}_{\text {fish }}$ is the nitrogen isotope signature of the fish, $\delta^{15} \mathrm{~N}_{\text {baseline }}$ is the nitrogen isotope signature of the food base, and $\Delta^{15} \mathrm{n}$ is the estimate of the average fractionation of $\delta^{15} \mathrm{~N}$ from one trophic level to the next (Vander Zanden \& Rasmussen, 1999).

Next, we assigned a value of $3.4 \%$ for $\Delta^{15} n$ following Post (2002). Differences in the $\delta^{13} \mathrm{C}$ of basal resources among sites were corrected using the following equation (Olsson, Stenroth, Nyström, \& Granéli, 2009):

$$
\delta^{13} \mathrm{Ccorr}_{\text {fish }}=\frac{\delta^{13} \mathrm{C}_{\text {fish }}-\delta^{13} \mathrm{CM}_{\text {baseline }}}{\delta^{13} \mathrm{CR}_{\text {baseline }}}
$$

where $\delta^{13} \mathrm{Ccorr}_{\text {fish }}$ is the corrected $\delta^{13} \mathrm{C}$ value of each individual fish, $\delta^{13} C_{\text {fish }}$ represents the $\delta^{13} \mathrm{C}$ ratio for the given fish, $\delta^{13} \mathrm{CM}_{\text {baseline }}$ is the mean $\delta^{13} \mathrm{C}$ value of primary consumers used as the baseline for calculating trophic position (i.e. collector-gatherer invertebrates), and $\delta^{13} \mathrm{CR}_{\text {baseline }}$ is the carbon range $\left(\delta^{13} C_{\max }-\delta^{13} C_{\min }\right)$ for the same primary consumers.

Niche width for the fish at each site was calculated from the corrected carbon and nitrogen isotope data by measuring the total area (TA) contained by a convex hull (smallest polygon containing all isotope values) in the corrected $\delta^{13} \mathrm{C}$ and $\delta^{15} \mathrm{~N}$ niche space (Layman, Arrington, Montaña, \& Post, 2007). Given the sensitivity of convex hull TA measures to extreme values and differences in sample size (Syväranta, Lensu, Marjomäki, Oksanen, \& Jones, 2013), we also calculated the standard ellipse area (SEA) for the corrected isotope data of each species following the methods detailed by Jackson, Inger, Parnell, and Bearhop (2011). In brief, the standard ellipse for a set of bivariate data (in this case TP vs. $\delta^{13}$ Ccorr corrected isotope space) is calculated from its variance and covariance and contains approximately $40 \%$ of the data (Jackson et al., 2011), hence revealing the core niche area that is largely insensitive to sample size fluctuations and extreme values. SEA was then corrected $\left(S_{E A}\right)$ to minimise bias caused by small sample sizes using an ( $n-2)$ correction on the denominator (Jackson et al., 2011, 2012) using the equation:

$$
\mathrm{SEA}_{C}=\mathrm{SEA} \times[(n-1) /(n-2)]
$$

The corrected standard ellipse areas and convex hulls allowed for graphical representation of the standard ellipse area of each fish species' isotopic composition (in corrected isotope space). Stable isotope Bayesian ellipses further allowed us to quantitatively compare differences in niche width (dispersion) between the two fish species, as well as the amount of niche overlap. Significant overlap between species is considered here to be $>0.6$, the same criterion adopted in the Schoener diet overlap index (Schoener, 1968) and more recently suggested as a benchmark for stable isotope comparisons of niche overlap (Guzzo, Haffner, Legler, Rush, \& Fisk, 2013). We used a Bayesian approach $\left(S_{B} A_{B}\right.$ ) to calculate credible confidence intervals for the estimated ellipse areas (Jackson et al., 2011). To test for significant differences in the area of ellipses (as a proxy for niche breadth), we ran 100,000 Markov chain Monte Carlo iterations for SEA $A_{B}$ and constructed 50, 70 and 95\% confidence intervals around the mean of each fish species. The probability that there was a significant difference in SEA $_{B}$ between the two fish species was assessed by calculating the proportion of iterations where the posterior estimate of ellipse area for one species was smaller than the other (Turner, Collyer, \& Krabbenhoft, 2010). SEA was considered to be significantly different among species when $5 \%$ or less of the posterior estimates for one species were smaller than that of the other $(a=.05)$. All Bayesian ellipse techniques and convex hull area calculations were performed using the SIAR package (Parnell, Inger, Bearhop, \& Jackson, 2010) run in R 3.1.1 (R Development Core Team 2014).

\section{3 | RESULTS}

\section{1 | Gut contents analysis}

A total of $n=89$ trout and $n=102$ redfin were collected and subjected to GCA. Of these, nine trout and six redfin had empty stomachs and were therefore excluded from further analyses, leaving sample sizes of $n=80$ for trout and $n=96$ for redfin. Our sampling gear was not size-selective, and the lengths of redfin and trout analysed ranged from 22 to $119 \mathrm{~mm}(\mathrm{TL})$ and 46 to $258 \mathrm{~mm}$ (TL) respectively, which is comparable to the range of sizes for each species present in CFR headwater streams (Shelton, Samways, Day, \& Woodford, 2016; Shelton et al., 2014a). A full list of food items found in the guts of redfin and trout, and their mean proportional weights $(\% \mathrm{~W})$ are listed in Table S1. The PERMDISP test revealed that the multivariate dispersion of the redfin data cloud was higher than that of the trout data cloud $\left(F_{1,174}=4.01, p=.014\right)$, implying that the diet breadth of redfin was greater than that of trout (mean distance to centroid for the redfin data was 51.51, while for trout, it was 42.61). Furthermore, the relatively high level of overall dissimilarity ( 88\%) between trout and redfin \%W data clouds suggests that diet overlap between species was low. The PCO ordination (two axes collectively explaining $44.04 \%$ of the total variation in the multivariate data clouds) revealed some separation of the trout and redfin data sets, but that there was also some overlap between the two data sets (Fig. 1a). This pattern indicates that there were some consistent differences in gut content composition between the two species, and the nested two-way PERMANOVA indicated 


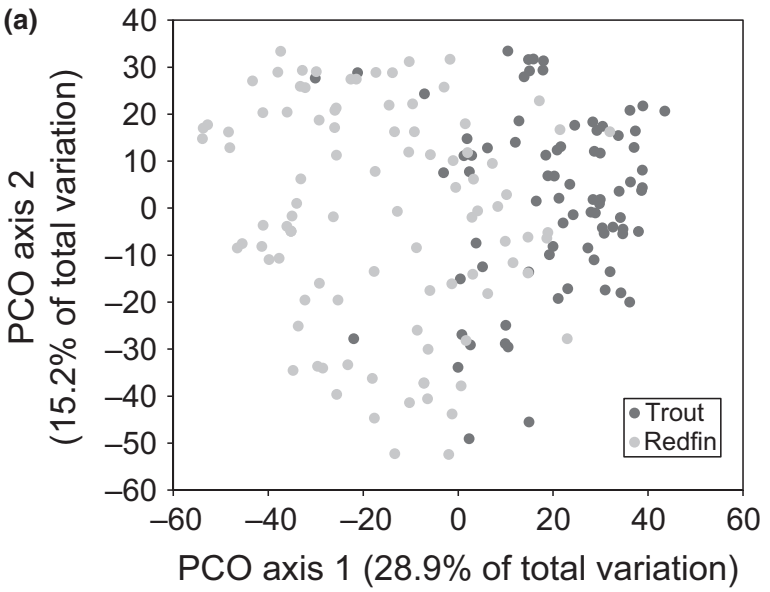

(b)

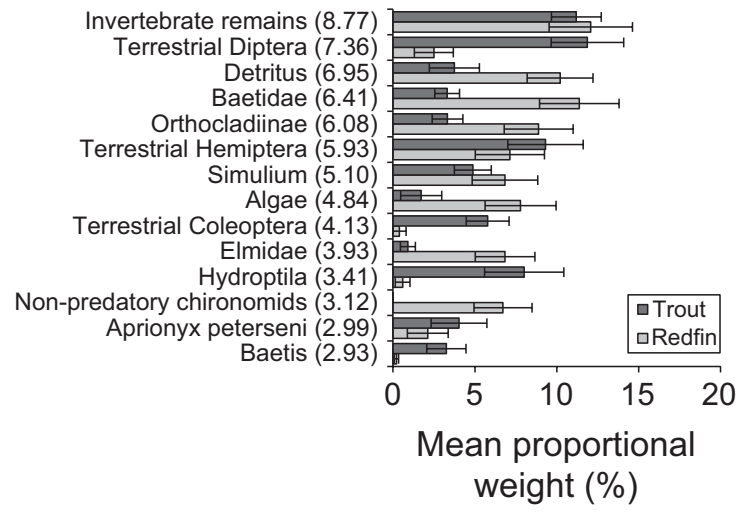

FIGURE 1 (a) Principal coordinate analysis (PCO) ordination of unaggregated (i.e. finest level of taxonomic resolution), weight-based gut content composition data for trout $(n=80)$ and redfin $(n=96)$ at the six sampling sites, and (b) mean $\pm S E$ percentage weight of the taxa contributing the most to the overall dissimilarity in gut content composition between trout and redfin, according to the SIMPER analyses. The average dissimilarity between trout and redfin gut contents was $88.11 \%$, and values in parentheses indicate the percentage contribution of each taxon to this dissimilarity

that both species and site had a significant effect on gut content composition (Table 1). Results of the SIMPER analysis (Fig. 1b) revealed that unidentifiable invertebrate remains were the single most important food item discriminating between the diets of trout and redfin, contributing $8.48 \%$ to the overall dissimilarity, suggesting that these species may differ in their relative abilities to digest prey beyond recognition. However, there was little difference in the mean percentage weight of this food category between species. Terrestrial invertebrates, in particular those within the families Diptera, Hemiptera and Coleoptera, were among the set of food items that contributed most strongly to the overall dissimilarity between species, and the mean percentage weight of each of these food items in the guts of trout was notably greater than in the guts of redfin. Collector-gatherer aquatic invertebrates, including Baetidae, Elmidae, Orthocladiinae, other Chironomidae (non-Tanypodinae), Aprionyx peterseni and Baetis, were also identified as important, and the mean percentage weight of these food items in the guts of redfin tended to be greater than in the guts of trout. The grazer-scraper Hydroptila, and the filter-feeder Simulium, also featured in the set of important contributors, and while Simulium had a greater mean percentage weight in the guts of redfin, Hydroptila had a greater mean percentage weight in the guts of trout. Finally, algae were also identified as important in discriminating between the diets of redfin and trout, contributing more to the gut contents of redfin than trout.

The proportion of aquatic invertebrates in the diet of redfin (\%W $=57.36)$ was greater, but not significantly so, than that in the diet of trout (\%W $=43.89$, Table 1, Fig. 2a). Of the different FFGs of aquatic invertebrates, collector-gatherers constituted by far the greatest proportion of redfin and trout gut contents, and the proportion of collector-gatherers in the diet of redfin $(\% \mathrm{~W}=33.65)$ was significantly greater $(p=.042)$ than that in the diet of trout (\%W = 16.17, Table 1, Fig. 2c). Filter feeders, grazer-scrapers, shredders and predators were less important components in the diets of both species than were collector-gatherers. Each of these groups constituted $<15 \%$ of the gut contents of redfin and trout, and no significant interspecies differences in the proportional contribution of these groups were detected. The proportion of terrestrial invertebrates in the diet of trout $(\% \mathrm{~W}=38.67)$ was significantly greater ( $p=.033)$ than that in the diet of redfin $(\% W=12.39 \%$, Table 1 , Fig. 2a). Plant material made up $\sim 18 \%$ of redfin diet, but only $~ 5 \%$ of trout diet, and the mean proportional weights of algae $(p=.038)$ and detritus ( $p=.046)$ in the guts of redfin $(7.79 \%$ and $10.20 \%$ respectively) were significantly greater than the mean proportional weights of these food categories in the guts of trout $(<5 \%$ for both algae and detritus, Table 1, Fig. 2b). Finally, there were significant "site effects" on the \%W of filter feeders, grazer-scrapers, predators and "other," indicating that the contributions of these food items to fish diets varied significantly among sites (Table 1 ). While $p$-values $<.05$ constitute a significant difference, here we interpret the $p$-values between .01 and .05 as providing some, but not strong evidence for a statistical significance (Zar, 1999).

The patterns of feeding selectivity displayed by trout and redfin were broadly similar, yet there were also some notable differences in their preferences for certain prey types (Fig. 3). Collectorgatherers and grazer-scrapers dominated the benthic invertebrate samples (Table S2), and trout and redfin differed in their selectivity for these FFGs (Fig. 3a). Redfin displayed a moderate $(0.25<L<0.5)$ preference for collector-gatherers, while this FFG was only weakly selected by trout $(0<L<0.25)$, and this difference was statistically significant ( $p=.017$, Table 2). Both species displayed moderate avoidance for grazer-scrapers $(-0.5<L<-0.25)$, but the $L$-value for redfin was somewhat, but not significantly, lower than that of trout. The abundance of filter feeders, predators and shredders in the benthic samples was low relative to the other FFGs, and these groups were consumed roughly in proportion to their availability (i.e. $-0.25<L<+0.25)$. The significant site effect detected for collectorgatherers, grazer-scrapers, shredders and predators (Table 2 ) implies that selectivity for these FFGs was highly variable among sites. The drift samples were dominated by aquatic invertebrates at most sites 
TAB LE 1 Multivariate and univariate nested PERMANOVA models examining effects of fish species and sampling site on proportional weight $(\% W)$ of food sources

\begin{tabular}{|c|c|c|c|c|c|c|}
\hline Response variable & Source & $d f$ & SS & MS & Pseudo-F & $p$ (perm) \\
\hline \multirow[t]{4}{*}{ Multivariate PERMANOVA } & Species & 1 & 58,597 & 58597.0 & 3.56 & $.038^{*}$ \\
\hline & Site (species) & 4 & 66,615 & 16654.0 & 5.51 & $.001^{*}$ \\
\hline & Residual & 170 & $5,136,100$ & 3021.2 & & \\
\hline & Total & 175 & 639,170 & & & \\
\hline \multicolumn{7}{|l|}{ Univariate PERMANOVA } \\
\hline \multirow[t]{2}{*}{ Plant material } & Species & 1 & 54.30 & 54.30 & 13.60 & $.045^{*}$ \\
\hline & Total & 175 & 405.79 & & & \\
\hline \multirow[t]{4}{*}{ Algae } & Species & 1 & 17.24 & 17.24 & 3.11 & $.038^{*}$ \\
\hline & Site (species) & 4 & 22.44 & 5.61 & 5.31 & $.001^{*}$ \\
\hline & Residual & 170 & 179.71 & 1.06 & & \\
\hline & Total & 175 & 222.60 & & & \\
\hline \multirow[t]{4}{*}{ Aquatic invertebrates } & Species & 1 & 4.50 & 4.50 & 0.84 & .543 \\
\hline & Site (species) & 4 & 21.56 & 5.39 & 2.68 & .032 \\
\hline & Residual & 170 & 341.34 & 2.01 & & \\
\hline & Total & 175 & 366.35 & & & \\
\hline \multirow[t]{4}{*}{ Collector-gatherers } & Species & 1 & 25.30 & 25.30 & 31.05 & $.042^{*}$ \\
\hline & Site (species) & 4 & 3.18 & 0.79 & 0.36 & .820 \\
\hline & Residual & 170 & 376.05 & 2.21 & & \\
\hline & Total & 175 & 404.56 & & & \\
\hline \multirow[t]{4}{*}{ Filter feeders } & Species & 1 & 3.12 & 3.12 & 0.44 & .539 \\
\hline & Site (species) & 4 & 28.98 & 7.25 & 4.18 & $.002^{*}$ \\
\hline & Residual & 170 & 295.00 & 1.74 & & \\
\hline & Total & 175 & 327.45 & & & \\
\hline \multirow[t]{4}{*}{ Shredders } & Species & 1 & 0.30 & 0.30 & 1.13 & .423 \\
\hline & Site (species) & 4 & 1.06 & 0.27 & 1.44 & .182 \\
\hline & Residual & 170 & 31.37 & 0.18 & & \\
\hline & Total & 175 & 32.64 & & & \\
\hline \multirow[t]{4}{*}{ Terrestrial invertebrates } & Species & 1 & 168.88 & 168.88 & 80.08 & $.033^{*}$ \\
\hline & Site (species) & 4 & 8.40 & 2.10 & 0.78 & .557 \\
\hline & Residual & 170 & 458.91 & 2.70 & & \\
\hline & Total & 175 & 635.63 & & & \\
\hline \multirow{4}{*}{$\begin{array}{l}\text { Unidentifiable invertebrate } \\
\text { remains }\end{array}$} & Species & 1 & 30.26 & 30.26 & 15.10 & .090 \\
\hline & Site (species) & 4 & 8.00 & 2.00 & 0.86 & .475 \\
\hline & Residual & 170 & 393.07 & 2.31 & & \\
\hline & Total & 175 & 431.28 & & & \\
\hline \multirow[t]{4}{*}{ Other } & Species & 1 & 1.86 & 1.86 & 2.24 & .209 \\
\hline & Site (species) & 4 & 3.37 & 0.84 & 3.85 & $.005^{*}$ \\
\hline & Residual & 170 & 37.16 & 0.22 & & \\
\hline & Total & 175 & 42.03 & & & \\
\hline
\end{tabular}

The multivariate model tested for overall differences in diet composition, while the univariate models tested for differences in each food source separately. An asterisk indicates a significant difference at $a=.05$.

(Table S2), and this prey type was selected significantly more strongly by redfin than by trout ( $p=.001$, Fig. 3b, Table 2 ). On the other hand, terrestrial invertebrates were strongly avoided by redfin, but not by trout (Fig. 3b), and the difference in selectivity between fish species for terrestrial invertebrates was also statistically significant $(p=.001$, Table 2). 


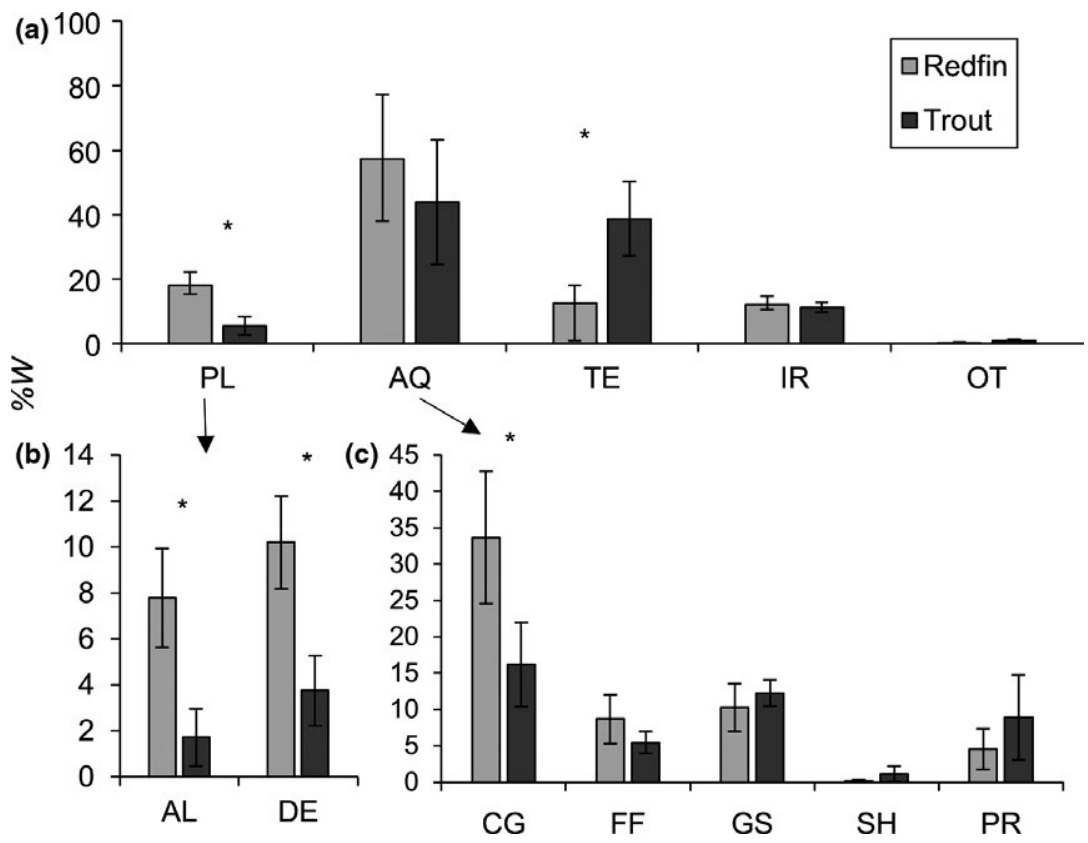

FIGURE 2 Mean \pm standard error (SE) proportional weight (\%W) of food items in the guts of trout (dark grey bars, $n=80$ ) and redfin (light grey bars, $n=96$ ). Panel (a) shows algae and detritus aggregated into "plant material" and aquatic invertebrate functional feeding groups aggregated into "aquatic invertebrates." Codes indicate PL, plant material; AQ, aquatic invertebrates; TE, terrestrial invertebrates; IR, unidentifiable invertebrate remains; OT, other; AL, algae; DE, detritus; CG, collector-gatherers; FF, filter feeders; GS, grazer-scrapers; SH, shredders; PR, predators. An asterisk indicates a significant difference at $\alpha=.05$
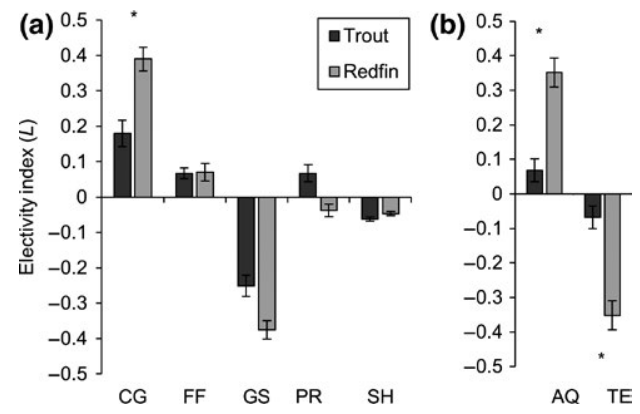

FIGURE 3 Mean electivity values (Strauss's $L, \pm 1 S E$ ) for trout $(n=80)$ and redfin $(n=96)$ for (a) the aquatic invertebrate functional feeding groups collector-gatherers (CG), filter feeders (FF), grazerscrapers (GS), predators (P)and shredders (SH) relative to their abundance in the benthos, and (b) for terrestrial (TE) and aquatic (AQ) invertebrates relative to their abundance in the drift. Asterisks indicate a significant difference at the $a=.05$ level

\section{2 | Stable isotope analysis}

The corrected standard ellipse areas (SEA ${ }_{C}$ ) for trout and redfin trophic niches were 3.09 and 8.92 respectively, while the areas of the convex hulls were 9.67 and 29.95 for trout and redfin respectively. These ellipse and hull sizes are visually presented in Fig. 4a. The width (dispersion) of the redfin trophic niche is considerably larger than that of trout according to the relative sizes of both the ellipse and convex hulls. Using confidence intervals obtained from Bayesian estimation of trophic niche size $\left(S_{E} A_{B}\right.$,
Fig. 4b), we found that all the posterior ellipses for trout were smaller than that of redfin and conclude that the difference in ellipse size between the two species, and hence the difference in core trophic niche width, was highly significant $(p<.001)$. The SEA $_{C}$ overlap between trout and redfin constituted a proportion of 0.82 and 0.29 of total trout and redfin isotopic niche area respectively. Therefore, redfin occupied a significant proportion of the trophic niche of trout (overlap >0.6) and appear to exploit a broader range of resources than do trout, given the small proportion of the redfin trophic niche occupied by trout (0.285). The confidence intervals around mean ellipse sizes estimates (Fig. 4b) further indicated that, although the mean ellipse area estimate for redfin was markedly larger than that of trout, there was more uncertainty around the estimate for redfin. Despite this uncertainty, the lowest estimates (95\% confidence) of ellipse area for redfin are still considerably higher than those reported for the upper 95\% confidence estimates for trout.

\section{4 | DISCUSSION}

Differences in food web structure between trout-free streams where native redfin are abundant and streams where non-native trout have replaced redfin as the numerically dominant fish species may be a result of differences in the trophic niches exploited by these species. In this study, we used two complementary approaches, GCA and SIA, to characterise and compare the trophic niches and 
TABLE 2 Univariate nested PERMANOVA models examining the effect of the fish species and sampling site on selection (Strauss' L) for aquatic and terrestrial invertebrate prey

\begin{tabular}{|c|c|c|c|c|c|c|}
\hline Response variable & Source & $d f$ & SS & MS & Pseudo-F & $p$ (perm) \\
\hline \multirow[t]{4}{*}{ Aquatic invertebrates } & Species & 1 & 8.25 & 2.06 & 27.62 & $.001^{*}$ \\
\hline & Site (species) & 4 & 3.05 & 3.05 & 1.49 & .273 \\
\hline & Residual & 170 & 12.02 & 0.07 & & \\
\hline & Total & 175 & 23.63 & & & \\
\hline \multirow[t]{4}{*}{ Collector-gatherers } & Species & 1 & 1.56 & 1.56 & 6.44 & $.017^{*}$ \\
\hline & Site (species) & 4 & 0.97 & 0.24 & 2.65 & $.041^{*}$ \\
\hline & Residual & 170 & 14.11 & 0.09 & & \\
\hline & Total & 175 & 16.85 & & & \\
\hline \multirow[t]{4}{*}{ Filter feeders } & Species & 1 & 0.00 & 0.00 & 0.02 & .939 \\
\hline & Site (species) & 4 & 0.25 & 0.06 & 1.89 & .113 \\
\hline & Residual & 170 & 5.19 & 0.03 & & \\
\hline & Total & 175 & 5.45 & & & \\
\hline \multirow[t]{4}{*}{ Grazer-scrapers } & Species & 1 & 0.57 & 0.57 & 0.65 & .546 \\
\hline & Site (species) & 4 & 3.51 & 0.88 & 23.27 & $.001^{*}$ \\
\hline & Residual & 170 & 5.80 & 0.04 & & \\
\hline & Total & 175 & 9.93 & & & \\
\hline \multirow[t]{4}{*}{ Predators } & Species & 1 & 0.36 & 0.36 & 3.59 & .104 \\
\hline & Site (species) & 4 & 0.41 & 0.10 & 3.04 & $.02^{*}$ \\
\hline & Residual & 170 & 5.14 & 0.03 & & \\
\hline & Total & 175 & 5.99 & & & \\
\hline \multirow[t]{4}{*}{ Shredders } & Species & 1 & 0.01 & 0.01 & 0.07 & .697 \\
\hline & Site (species) & 4 & 0.28 & 0.07 & 77.57 & $.001^{*}$ \\
\hline & Residual & 170 & 0.14 & 0.00 & & \\
\hline & Total & 175 & 0.42 & & & \\
\hline \multirow[t]{4}{*}{ Terrestrial invertebrates } & Species & 1 & 8.25 & 2.06 & 27.62 & $.001^{*}$ \\
\hline & Site (species) & 4 & 3.05 & 3.05 & 1.49 & .277 \\
\hline & Residual & 170 & 12.02 & 0.07 & & \\
\hline & Total & 175 & 23.63 & & & \\
\hline
\end{tabular}

An asterisk indicates a significant difference at $a=.05$.

diet composition of trout and redfin in three headwater streams each. Taken together, our results indicate that native redfin exploit a broader trophic niche, and more omnivorous diet, than do trout. Our GCA analysis also alludes to differences in the contributions of different invertebrate prey types to the diets of trout and redfin (discussed below), and overall, our findings suggest that the replacement of native redfin by non-native trout has reduced top-down control over collector-gatherer aquatic invertebrates in CFR headwater streams.

Surveys of benthic communities in CFR headwater streams show that herbivorous benthic invertebrates, particularly collector-gatherer and grazer-scraper taxa, are more abundant in streams where trout have replaced small-bodied native fishes (Shelton et al., 2014b), suggesting that native fishes prey more heavily on these benthic invertebrates than do trout. Data on the feeding habits of Cape galaxias and Cape kurper are scarce, but available information suggests that both species feed primarily on benthic invertebrates (Skelton, 2001). Thus, removal of these species could potentially contribute towards higher abundances of herbivorous benthic invertebrates in trout-invaded streams, but more data on their diets are needed to adequately evaluate this hypothesis. Our GCA results in the present study largely support the notion that redfin are stronger regulators of collectorgatherer taxa than are trout. Unexpectedly, redfin appeared to avoid grazer-scraper taxa which is inconsistent with the pattern described by Shelton et al. (2014b). However, this result may be an artefact of the fact that Strauss' $L$ is based on proportional availabilities and utilisations of the various prey types, and the relatively high consumption of collector-gatherers might have masked consumption of grazerscrapers. Regardless, our findings are broadly consistent with those of de Wet (1990), who performed GCA on 142 individuals of $P$. burchelli from other streams within the Breede River catchment, and found that while it utilised a wide variety of food sources including algae, detritus and sand, the species was primarily an opportunistic carnivore that fed mostly on benthic invertebrates. Moreover, de Wet's (1990) study reported that aquatic invertebrates comprised roughly $50 \%$ of gut contents by volume, and that collector-gatherer taxa tended to be the most important aquatic invertebrate prey occurring in redfin guts-findings comparable to those in the present study. This congruency between studies implies that redfin may have a widespread preference for feeding on aquatic invertebrates in the collector-gatherer FFG. However, the view that redfin are primarily benthic invertivores is not however in agreement with results from earlier studies investigating their diet (e.g. Cambray \& Stewart, 1985; Esterhuizen, 1978), which have reported mostly detritus and relatively little animal material in their guts. The discrepancy between these two sets of studies is possibly attributable to temporal variations in redfin diet (de Wet, 


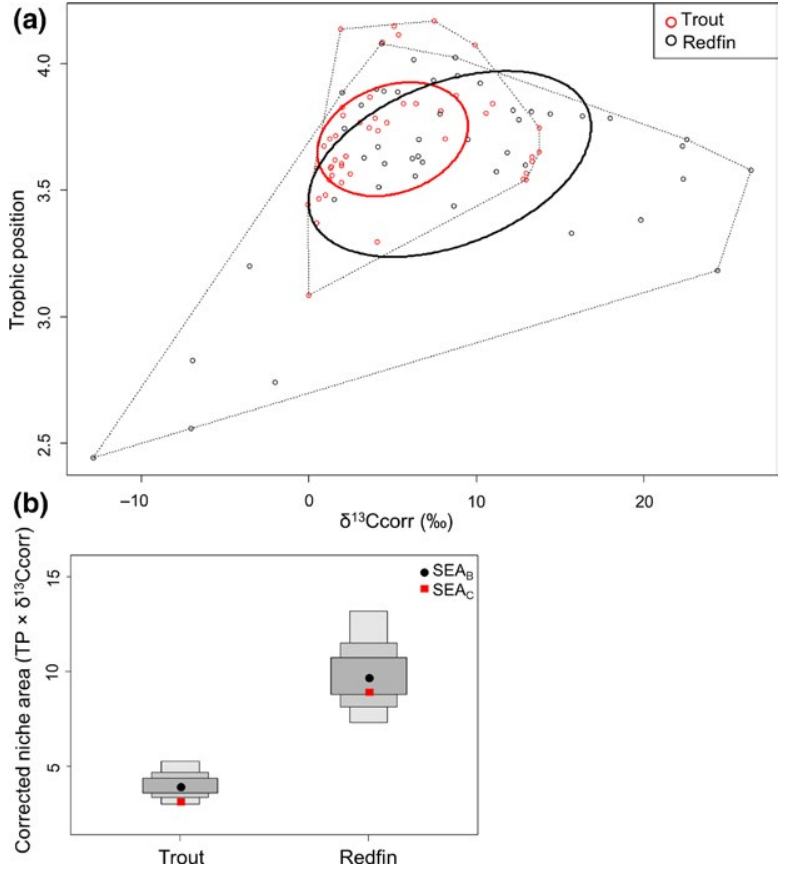

FIGURE 4 Stable isotope Bayesian ellipses and convex hulls for trout and redfin isotopic data depicted in (a) corrected bivariate isotope space (solid lines depict ellipses, dotted lines are convex hulls), and (b) as a density plot presenting the Bayesian estimates for confidence intervals of standard ellipse areas (black circles correspond to the Bayesian estimated means, red squares represent the calculated standard ellipse areas corrected for small sample size, and grey boxes represent confidence intervals of $50 \%, 75 \%$ and 95\%). Each data point represents an individual fish (a), and in both plots, data have been pooled across the three sites sampled for each of the fish species

1990), and/or differences in food availability among sampling sites. Indeed, the diet of stream fish can vary temporally (over both diel and seasonal scales) as well as spatially, and it remains unclear whether our summer snapshot sample of fish diet composition is representative of fish dietary habits in these streams in general. We encourage future studies to expand the spatial and temporal scales of our study and thereby assess the generality of our findings.

Rainbow trout, although capable of consuming considerable quantities of aquatic invertebrates (Buria, Albariño, Modenutti, \& Balseiro, 2009; Huryn, 1998), are drift feeders, and their diet can be influenced by the availability of different food sources in the drift (Laudon, Vondracek, \& Zimmerman, 2005; Nakano et al., 1999). Elsewhere, it has been found that terrestrial invertebrates can constitute a large proportion of trout diets (Baxter et al., 2004; Kawaguchi \& Nakano, 2001; Nakano et al., 1999; White \& Harvey, 2007), but this is not always the case, and in some instances, their occurrence in trout diet is rare (Buria et al., 2009; Huryn, 1998). The degree to which trout rely on terrestrial prey appears to be linked to the relative availability of aquatic versus terrestrial prey in the drift (Buria et al., 2009; Nakano et al., 1999), which in turn is influenced by a suite of environmental factors such as the productivity of the aquatic system (Huryn, 1998) and the productivity of adjacent riparian habitats (Edwards \& Huryn,
1996). Productivity in headwater streams in the CFR is generally relatively low (de Moor \& Day, 2013), but that in riparian habitats may be contrastingly high given that terrestrial invertebrates were relatively common in the drift at our study sites (Table S2). Our finding that terrestrial invertebrates were a relatively important component of trout diet (\%W approximately $40 \%$ for trout vs. $15 \%$ for redfin) suggests that trout take advantage of terrestrial subsidies in these streams more strongly than do redfin. That consumption of aquatic invertebrates by trout is offset by terrestrial prey could account for the relatively high abundance of benthic invertebrates in streams where trout have replaced benthic-feeding native fishes relative to that in uninvaded streams.

Reliable data on the diet of trout in CFR streams are surprisingly scarce, and to our knowledge, just two quantitative studies exist. Woodford (2002), who analysed the gut contents of 45 rainbow trout in the upper Berg River, found that the majority of their guts contained terrestrial invertebrates, and that terrestrial prey accounted for $54 \%$ and $14 \%$ of their gut contents by number in spring and autumn respectively (the remaining gut contents consisted of aquatic invertebrates, predominantly ephemeropterans and dipterans). Lamberth (2001) examined the gut contents of 11 trout collected from the Molenaars River (Breede River catchment) and found that while dominated by aquatic invertebrates (mostly final instar ephemeropterans emerging at the water's surface), terrestrial invertebrates were present in $50 \%$ of the guts examined. Taken together, these limited data and observations are broadly consistent with our results and suggest that terrestrial invertebrates frequently form an important part of the diet of trout in headwater streams in the CFR, as is the case in other parts of the world (Baxter et al., 2004; Kawaguchi \& Nakano, 2001; Nakano et al., 1999; White \& Harvey, 2007).

Two important sources of variation in fish diet relevant to the present study include the potential for ontogenetic shifts in feeding behaviour, and the influence of food availability on diet composition. As our fish-collecting methods were not size-selective, and as the ranges of lengths of trout and redfin analysed in this study cover the range of sizes for these species found in CFR headwater streams (Shelton et al., 2014a), we consider our results to be representative of naturally occurring populations. However, freshwater fishes commonly undergo ontogenetic shifts in feeding behaviour (Gelwick \& Matthews, 2007), and future studies should look to investigate ontogenetic shifts in the feeding behaviour of fishes inhabiting CFR headwater streams. Because the focus of the present study was on characterising and comparing the feeding habits of redfin and trout in allopatry rather than in sympatry, differences in the availability of different food types among sites could potentially confound interspecific differences in gut content composition. While there were clear differences in food availability between streams with and without trout (Shelton et al., 2014b), the main difference was that aquatic invertebrate abundance in streams with trout was approximately twice that in streams with no trout. Thus, despite the higher availability of aquatic invertebrate prey in invaded streams, they still contributed less to the gut contents of trout than to the gut contents of redfin (the opposite of what might be expected if the observed 
dietary differences were being driven by differences in prey availability among streams). Furthermore, differences in food availability between streams with and without trout were accounted for in the feeding selectivity analyses, and differences in stable isotope signatures of basal resources among streams were corrected. Thus, we argue that our comparisons of trout and redfin diet composition and niche breadth are robust and not masked by ambient differences in availability of different food sources.

Overall, the results from this study indicate that native redfin exploit a broader trophic niche, and more omnivorous diet, than do trout in the study streams. Our GCA analyses show terrestrial invertebrates to be a relatively important prey source for trout, potentially offsetting predation pressure on aquatic invertebrates in the streams where they have replaced redfin and the other small-bodied native species. On the other hand, redfin diet was dominated by aquatic invertebrates, with terrestrial prey a less important food source. These findings have important management implications because changes in the functioning of fish assemblages can potentially alter the structure and function of entire aquatic communities (Benjamin et al., 2011). Indeed, differences in community structure between streams with and without trout in the upper Breede River catchment (Shelton et al., 2014b) appear to be linked to differences in the trophic niches occupied by trout and redfin (Shelton et al., 2016) in that the relatively low density of benthic invertebrates in streams supporting healthy native fish populations (i.e. lacking trout) could be attributed to the fact that redfin are strongly reliant on aquatic invertebrate prey. Specifically, the relatively strong predation pressure exerted by redfin on herbivorous invertebrates, such as collector-gatherers, could account for their relatively low abundance at sites lacking trout, and also for the relatively high biomass of benthic algae at these sites. On the other hand, the high density of benthic invertebrates (and correspondingly low algal biomass) at sites where trout have established and replaced native fish could be a consequence of the important role of terrestrial invertebrates in trout diet, which could offset the predation pressure they exert on aquatic invertebrates. Our results provide evidence that the abovementioned trophic niche differentiation drives the communitywide changes that accompany trout invasion of headwater streams previously inhabited by redfin.

\section{ACKNOWLEDGEMENTS}

Financial support was from the DST-NRF Centre of Excellence for Invasion Biology (CIB), the German Academic Exchange Service (DAAD), the University of Cape Town (UCT) and the Cape Tercentenary Foundation. J Shelton acknowledges a UCT Postgraduate Publication Incentive Bursary. M Bird received a DST/ NRF Scarce-Skills Postdoctoral Fellowship. This research was conducted under permit 0035-AAA 007-00057 issued from CapeNature, and animal ethics clearance for the study was obtained from the University of Cape Town. Stable isotope analysis was conducted at the University of Cape Town's Stable Isotope Laboratory. L Phigeland and $\mathrm{K}$ Barnes assisted with laboratory work, and $\mathrm{K}$ Tilanus assisted with fieldwork.

\section{REFERENCES}

Anderson, C., \& Cabana, G. (2007). Estimating the trophic position of aquatic consumers in river food webs using stable nitrogen isotopes. Journal of the North American Benthological Society, 26, 273-285.

Anderson, M. J., Gorley, R. N., \& Clarke, K. R. (2008). PERMANOVA+ for PRIMER: Guide to software and statistical methods. Plymouth, UK: PRIMER-E.

Baxter, C. V., Fausch, K. D., Murakami, M., \& Chapman, P. L. (2004). Fish invasion restructures stream and forest food webs by interrupting reciprocal prey subsidies. Ecology, 85, 2656-2663.

Benjamin, J. R., Fausch, K. D., \& Baxter, C. V. (2011). Species replacement by a nonnative salmonid alters ecosystem function by reducing prey subsidies that support riparian spiders. Oecologia, 167, 503-512.

Bland, J. M., \& Altman, D. G. (1995). Multiple significance tests: The Bonferroni method. British Medical Journal, 310, 170.

Buria, L., Albariño, R., Modenutti, B., \& Balseiro, E. (2009). Temporal variations in the diet of the exotic rainbow trout (Oncorhynchus mykiss) in an Andean-Patagonian canopied stream. Revista Chilena de Historia Natural, 82, 3-16.

Cabana, G., \& Rasmussen, J. B. (1996). Comparison of aquatic food chains using nitrogen isotopes. Proceedings of the National Academy of Sciences, 93, 10844-10847.

Cabin, R. J., \& Mitchell, R. J. (2000). To Bonferroni or not to Bonferroni: When and how are the questions? Bulletin of the Ecological Society of America, 81, 246-248.

Cambray, J. A. (1983). The feeding habits of minnows of the genus Barbus (Pisces: Cyprinidae) in Africa, with special reference to Barbus anoplus Weber. Journal of the Limnological Society of Southern Africa, 9, 12-22.

Cambray, J. A. (2003). The global impact of alien trout species-a review; with reference to their impact in South Africa. African Journal of Aquatic Science, 28, 61-67.

Cambray, J. A., \& Stewart, T. C. (1985). Aspects of the biology of a rare redfin minnow, Barbus burchelli (Pisces, Cyprinidae), from South Africa. South African Journal of Zoology, 20, 155-165.

Chakona, A., \& Swartz, E. R. (2013). A new redfin species, Pseudobarbus skeltoni (Cyprinidae, Teleostei), from the Cape Floristic Region, South Africa. Zootaxa, 3686, 565-577.

Chalcraft, D. R., \& Resetarits, W. J. (2003). Predator identity and ecological impacts: Functional redundancy or functional diversity? Ecology, 84, 2407-2418.

Clarke, L. R., Vidergar, D. T., \& Bennett, D. H. (2005). Stable isotopes and gut content show diet overlap among native and introduced piscivores in a large oligotrophic lake. Ecology of Freshwater Fish, 14, 267-277.

Clarke, K. R., \& Warwick, R. M. (2001). Change in marine communities: An approach to statistical analysis and interpretation, 2nd ed. Plymouth, UK: PRIMER-E.

Correa, S. B., \& Winemiller, K. O. (2014). Niche partitioning among frugivorous fishes in response to fluctuating resources in the Amazonian floodplain forest. Ecology, 95, 210-222.

Cortés, E. (1997). A critical review of methods of studying fish feeding based on analysis of stomach contents: Application to elasmobranch fishes. Canadian Journal of Fisheries and Aquatic Sciences, 54, 726738.

Cox, J. G., \& Lima, S. L. (2006). Naiveté and an aquatic-terrestrial dichotomy in the effects of introduced predators. Trends in Ecology \& Evolution, 21, 674-680.

Crawford, S. S., \& Muir, A. M. (2008). Global introductions of salmon and trout in the genus Oncorhynchus: 1870-2007. Reviews in Fish Biology and Fisheries, 18, 313-344.

Cucherousset, J., Aymes, J. C., Santoul, F., \& Céréghino, R. (2007). Stable isotope evidence of trophic interactions between introduced brook trout Salvelinus fontinalis and native brown trout Salmo trutta 
in a mountain stream of south-west France. Journal of Fish Biology, 71, 210-223.

Cummins, K. W., Merritt, R. W., \& Berg, M. B. (2008). An introduction to the aquatic insects of North America (p. 1158). Dubuque, IA: Kendall/Hunt Publishing Company.

Edwards, E., \& Huryn, A. (1996). Effect of riparian land use on contributions of terrestrial invertebrates to streams. Hydrobiologia, 337, 151-159.

Esterhuizen, W. C. N. (1978). Die ekologie van Barbus burchelli A Smith, 1841 in die Keisersrivier. Kaap Provinsie: Thesis, Nelson Mandela Metropoli$\tan$ University.

Flecker, A. S., \& Townsend, C. R. (1994). Community-wide consequences of trout introduction in New Zealand streams. Ecological Applications, $4,798-807$.

Garamszegi, L. Z. (2006). Comparing effect sizes across variables: Generalization without the need for Bonferroni correction. Behavioral Ecology, 17, 682-687.

Gelwick, F. P., \& Matthews, W. J. (2007). Trophic relations of stream fishes. In F. R. Hauer, \& G. A. Lamberti (Eds.), Methods in stream ecology (pp. 611-636). Oxford, London, UK: Academic Press.

Gido, K. B., \& Franssen, N. R. (2007). Invasion of stream fishes into low trophic positions. Ecology of Freshwater Fish, 16, 457-464.

Guzzo, M. M., Haffner, G. D., Legler, N. D., Rush, S. A., \& Fisk, A. T. (2013). Fifty years later: Trophic ecology and niche overlap of a native and non-indigenous fish species in the western basin of Lake Erie. Biological Invasions, 15, 1695-1711.

Houlahan, J. E., Keddy, P. A., Makkay, K., \& Findlay, C. S. (2006). The effect of adjacent land use on wetland species richness and composition. Wetlands, 26, 79-96.

Huryn, A. D. (1998). Ecosystem-level evidence for top-down and bottomup control of production in a grassland stream system. Oecologia, 115, 173-183.

Hyslop, E. J. (1980). Stomach contents analysis-a review of methods and their application. Journal of Fish Biology, 17, 411-429.

Jackson, M. C., Donohue, I., Jackson, A. L., Britton, J. R., Harper, D. M., \& Grey, J. (2012). Population-level metrics of trophic structure based on stable isotopes and their application to invasion ecology. PLoS ONE, 7, e31757.

Jackson, A. L., Inger, R., Parnell, A. C., \& Bearhop, S. (2011). Comparing isotopic niche widths among and within communities: SIBERStable Isotope Bayesian Ellipses in R. Journal of Animal Ecology, 80, 595-602.

Jackson, M. C., Woodford, D. J., Bellingan, T. A., Weyl, O. L. F., Potgieter, M. J., Rivers-Moore, N. A., ... Chimimba, C. T. (2016). Trophic overlap between fish and riparian spiders: Potential impacts of an invasive fish on terrestrial consumers. Ecology and Evolution, 6, 1745-1752.

Kawaguchi, Y., \& Nakano, S. (2001). Contribution of terrestrial invertebrates to the annual resource budget for salmonids in forest and grassland reaches of a headwater stream. Freshwater Biology, 46, 303-316.

Lamberth, S. (2001). Chapter 8: Fish. In C. A. Brown (Ed.), Breede River basin study: Specialist reports for the ecological reserve (water quantity) determination for key river reaches Volume 1: Introduction, water quality and biology (pp. 1-72). Cape Town, South Africa: Southern Waters.

Laudon, M. C., Vondracek, B., \& Zimmerman, J. K. H. (2005). Prey selection by trout in a spring-fed stream: Terrestrial versus aquatic invertebrates. Journal of Freshwater Ecology, 20, 723-733.

Layman, C. A., Arrington, D. A., Montaña, C. G., \& Post, D. M. (2007). Can stable isotope ratios provide for community-wide measures of trophic structure? Ecology, 88, 42-48.

Leprieur, F., Hickey, M. A., Arbuckle, C. J., Closs, G. P., Brosse, S., \& Townsend, C. R. (2006). Hydrological disturbance benefits a native fish at the expense of an exotic fish. Journal of Applied Ecology, 43, 930-939.

Mack, R. N., Simberloff, D., Lonsdale, W. M., Evans, H., Clout, M., \& Bazzaz, F. A. (2000). Biotic invasions: Causes, epidemiology, global consequences, and control. Ecological Applications, 10, 689-710.
McDowall, R. M. (2006). Crying wolf, crying foul, or crying shame: Alien salmonids and a biodiversity crisis in the southern cool-temperate galaxioid fishes? Reviews in Fish Biology and Fisheries, 16, 233-422.

McIntosh, A. R., \& Townsend, C. R. (1995). Contrasting predation risks presented by introduced brown trout and native common river galaxias in New Zealand streams. Canadian Journal of Fisheries and Aquatic Sciences, 52, 1821-1833.

McIntosh, A. R., \& Townsend, C. R. (1996). Interactions between fish, grazing invertebrates and algae in a New Zealand stream: A trophic cascade mediated by fish-induced changes to grazer behavior? Oecologia, 108, 174-181.

de Moor, F. C., \& Day, J. A. (2013). Aquatic biodiversity in the mediterranean region of South Africa. Hydrobiologia, 719, 237-268.

Moran, M. D. (2003). Arguments for rejecting the sequential Bonferroni in ecological studies. Oikos, 102, 403-405.

Nakagawa, S. (2004). A farewell to Bonferroni: The problems of low statistical power and publication bias. Behavioral Ecology, 15, 10441045.

Nakano, S., Miyasaka, H., \& Kuhara, N. (1999). Terrestrial-aquatic linkages: Riparian arthropod inputs alter trophic cascades in a stream food web. Ecology, 80, 2435-2441.

Olsson, K., Stenroth, P., Nyström, P., \& Granéli, W. (2009). Invasions and niche width: Does niche width of an introduced crayfish differ from a native crayfish? Freshwater Biology, 54, 1731-1740.

Pace, M. L., Cole, J. J., Carpenter, S. R., \& Kitchell, J. F. (1999). Trophic cascades revealed in diverse ecosystems. Trends in Ecology \& Evolution, 14, 483-488

Parnell, A. C., Inger, R., Bearhop, S., \& Jackson, A. L. (2010). Source partitioning using stable isotopes: Coping with too much variation. PLoS ONE, 5, e9672.

Perneger, T. V. (1998). What's wrong with Bonferroni adjustments. British Medical Journal, 316, 1236-1238.

Picker, M. D., Griffiths, C. L., \& Weaving, A. (2004). Field guide to insects of South Africa (2nd ed.), (444 pp.). Cape Town, South Africa: Struik.

Post, D. M. (2002). Using stable isotopes to estimate trophic position: Models, methods, and assumptions. Ecology, 83, 703-718.

R Development Core Team (2014). R: A language and environment for Statistical Computing. R Foundation for Statistical Computing, Vienna. ISBN 3-900051-07-0, http://www.R-project.org/

Rahel, F. J. (2000). Homogenization of fish faunas across the United States. Science, 288, 854-856.

Schoener, T. W. (1968). The Anolis lizards of Bimini: Resource partitioning in a complex fauna. Ecology, 49, 704-726.

Scott, L. E. P., Skelton, P. H., Booth, A. J., Verheust, L., Harris, R., \& Dooley, J. (2006). Atlas of southern African freshwater fishes (303 pp). Grahamstown, South Africa: Smithiana.

Shelton, J. M., Samways, M. J., \& Day, J. A. (2014a). Predatory impact of non-native rainbow trout on endemic fish populations in headwater streams in the Cape Floristic Region of South Africa. Biological Invasions, 17, 365-369.

Shelton, J. M., Samways, M. J., \& Day, J. A. (2014b). Non-native rainbow trout change the structure of benthic communities in headwater streams of the Cape Floristic Region, South Africa. Hydrobiologia, 745, 1-15.

Shelton, J. M., Samways, M. J., Day, J. A., \& Woodford, D. J. (2016). Are native cyprinids or introduced salmonids stronger regulators of benthic invertebrates in South African headwater streams? Austral Ecology. DOI: 10.1111/aec.12352.

Simon, K. S., \& Townsend, C. R. (2003). Impacts of freshwater invaders at different levels of ecological organisation, with emphasis on salmonids and ecosystem consequences. Freshwater Biology, 48, 982-994.

Skelton, P. H. (2001). A complete guide to the freshwater fishes of southern Africa (2nd ed.). Cape Town, South Africa: Struik Publishers.

Steynor, A. C., Hewitson, B. C., \& Tadross, M. A. (2009). Projected future runoff of the Breede River under climate change. Water SA, 35, 433-440. 
Strauss, R. E. (1979). Reliability estimates for Ivlev's electivity index, the forage ratio, and a proposed linear index of food selection. Transactions of the American Fisheries Society, 108, 344-352.

Syväranta, J., Lensu, A., Marjomäki, T. J., Oksanen, S., \& Jones, R. I. (2013). An empirical evaluation of the utility of convex hull and standard ellipse areas for assessing population niche widths from stable isotope data. PLoS ONE, 8, e56094.

Townsend, C. R. (2003). Individual, population, community, and ecosystem consequences of a fish invader in New Zealand streams. Conservation Biology, 17, 38-47.

Townsend, C. R., \& Crowl, T. A. (1991). Fragmented population structure in a native New Zealand fish: An effect of introduced brown trout? Oikos, 61, 347-354.

Turner, T. F., Collyer, M. L., \& Krabbenhoft, T. J. (2010). A general hypothesistesting framework for stable isotope ratios in ecological studies. Ecology, 91, 2227-2233.

Vander Zanden, M. J., \& Rasmussen, J. B. (1999). Primary consumer $\delta^{13} \mathrm{C}$ and $\delta^{15} \mathrm{~N}$ and the trophic position of aquatic consumers. Ecology, 80, 1395-1404.

de Wet, S. (1990). The feeding ecology of the redfin minnow P. burchelli (Cyprinidae) in the Steenboks and Hex tributaries of the Breede River system. Thesis, Stellenbosch University.
White, J. L., \& Harvey, B. C. (2007). Winter feeding success of stream trout under different streamflow and turbidity conditions. Transactions of the American Fisheries Society, 136, 1187-1192.

Whitehead, A., Weyl, O. L. F., \& Bills, I. R. (2007). Reproductive and feeding biology of the endangered fiery redfin, Pseudobarbus phlegethon (Barnard 1938) (Teleostei: Cyprinidae), in the Noordhoeks River, South Africa. African Journal of Aquatic Science, 32, 281-290.

Woodford, D. J. (2002). Preliminary investigation into the impact of rainbow trout (Oncorhynchus mykiss) on the indigenous fishes of the upper Berg River. South Africa: Thesis, University of Cape Town.

Zar, J. H. (1999). Biostatistical analysis (4th ed.). NJ: Prentice Hall. Englewood Clifffs, New Jersey.

\section{SUPPORTING INFORMATION}

Additional supporting information may be found in the online version of this article at http://onlinelibrary.wiley.com/doi/10.1111/ eff.12293/suppinfo 